Amilcar O. Herrera, coordenador do Instituto de Geociências da Unicamp, professor visitante da

\author{
Amilcar O. Herrera
}

Universidade de Sussex, membro da

Fundacion Bariloche, ex-professor da Universidade de Buenos Aires.

\title{
Transferência de tecnologia e meio ambiente
}

\section{O marco histórico}

Não é novo o papel social determinante da tecnologia e da sua transferência: é fenômeno que sempre ocorreu ao longo da história. No entanto, nunca no passado os seus efeitos foram tão generalizados nem tão penetrantes em todas as atividades da sociedade receptora. A razão disso não se baseia apenas no fato de que a tecnologia moderna é bem mais eficiente do que as anteriores, como se pode constatar numa breve revisão histórica.

Em qualquer cultura há que se identificar, concomitantemente com a tecnologia, um conjunto de idéias e conhecimentos essencialmente explicativos e que incluem a religião, as superstições, a filosofia e a ciência. O conhecimento científico sempre existiu, ainda que em forma rudimentar, mesmo nas primeiras etapas da civilização.

Nas culturas antigas, a tecnologia possuía duas características principais: era muito simples e o conhecimento em que se baseava era compartiIhado praticamente por toda a comunidade. Neste sentido, era parte integrante da cultura social e individual. Por outro lado, não era científica; sua base era empírica e pouca ou nenhuma conexão tinha com o corpo de conhecimentos explicativos.

Quando a tecnologia era transferida, seu efeito social era restringido por vários fatores: em primeiro lugar, como essas tecnologias se incorporavam facilmente na sociedade receptora, elas não criavam uma dependência significativa da sociedade ofertante: em segundo lugar, como não eram essencialmente científicas, a sua introdução tinha pouco efeito so- bre o conjunto dos conhecimentos explicativos que constituem o núcleo vivo de toda a cultura; e finalmente, como a introdução e dissiminação das novas tecnologias eram um processo muito lento, havia muito tempo para que a sociedade receptora introduzisse as necessárias adaptações sem efeitos aberrantes sobre a cultura.

A separação entre ciência e tecnologia mantém-se sem grandes alterações até uma data avançada da Revolução Industrial. A característica mais importante deste processo, do ponto de vista de nossa análise, é que ele não foi desencadeado pela revolução científica, iniciada séculos antes, mas sim por fatores sócio-econômicos. Só na segunda etapa da Revolução Industrial, com a exigência da indústria química e a introdução da eletricidade, é que a tecnologia baseada na ciência se incorpora realmente no desenvolvimento industrial. Durante o presente século, as duas guerras mundiais, a competição pelo poder e pelo prestígio e o controle do mercado mundial pelas grandes potências converteram a tecnologia no real paradigma do progresso.

A introdução da tecnologia científica originou um fenômeno que determina em grande parte as características do mundo moderno. A criação de tecnologia, que durante toda a história foi uma atividade comum a todas as sociedades, converte-se cada vez mais, no privilégio de um pequeno grupo de paises e, dentro destes, de organizações e empresas que podem financiar seus custos sempre crescentes. Para uma grande parte da humanidade, e particularmente para os países em desenvolvimento, a tecnologia converteu-se num fator exógeno. 
A transferência unidirecional indiscriminada de tecnologia no mundo atual (com seus valores sociais e culturais implícitos) não se pode explicar apenas pela superioridade da tecnologia ocidental. Mesmo sem discutir essa superioridade em termos de produtividade, a verdade é que muitos países em desenvolvimento têm uma capacidade muito maior de adaptá-la às suas próprias condições sociais e culturais do que aquela que utilizam no processo de transferência. Por outro lado, acontece que muitas tecnologias foram adotadas mesmo quando a sua eficiência, em termos gerais de economia e ambiente, não era superior à das que estavam em uso nas sociedades receptoras.

\section{Transferência de tecnologia e impacto ambiental}

O fato de os países subdesenvolvidos utilizarem tecnologias importadas indiscriminadamente tem uma importância fundamental em função do seu efeito sobre o meio ambiente. Analisaremos a seguir e sucintamente as diferenças entre os países centrais e os periféricos quanto ao efeito ambiental das referidas tecnologias e no que diz respeito à sua capacidade de controlá-lo.

\section{Adequação das tecnologias ao meio ambiente}

Todas as sociedades criaram, mediante um longo processo de tentativas sucessivas, tecnologias adequadas a seu meio ambiente físico e humano. Os países atualmente desenvolvidos não são uma exceção. As tecnologias que criaram a partir da Revolução Industrial correspondiam também a suas características específicas: dotação de recursos naturais e humanos, condições ecológicas, etc. E isso não significa que não tenha também produzido efeitos nocivos sobre o meio ambiente; estes foram, todavia, corrigidos, pelo menos em parte, por um esforço contínuo de adequação. O acelerado aumento de deterioração ambiental, registrado, sobretudo, a partir da Segunda Guerra Mundial, deve-se, talvez, tanto ao incontrolado crescimento do consumo com a conseqüente enorme demanda de recursos naturais - os energéticos, inclusive - quanto às características intrinsecamente antiecológicas das tecnologias utilizadas. Em outros termos: o efeito negativo é tanto conseqüência da intensidade do uso como da qualidade das tecnologias.

Quando estas tecnologias são transferidas para países com meios físicos e sociais diferentes, essa adaptação, pelo menos em parte, desaparece e seu efeito ambiental pode tornar-se muito mais nocivo. Entre os muitos exemplos conhecidos desse efeito pode-se citar a habitação, incluindo os grandes edifícios públicos.

As grandes construções de ferro e cimento com paredes de vidro foram concebidas para países de clima temperado ou frio, onde faz sentido a maior captação possível de radiação solar. Estes edifícios, contudo, foram adotados também em países tropicais com a conseqüência de que isso requer uma enorme quantidade de energia para resfriá-los, dada a grande quantidade de radiação qua captam todo o ano. Na habitação familiar ocorre um fenômeno semelhante: a casa-habitação, construída à base de cimento, ferro e cerâmica, destronou, sobretudo por razões de status social imposto pela cultura dominante, as vivendas tradicionais construídas com materiais locais mais baratos e de melhores condições térmicas. Isso se vê muito na América Latina, sobretudo nas áreas rurais, onde a vivenda tradicional, ampla, construída com materiais locais e de excelentes condições térmicas, vem sendo substituída por moradias "modernas", pequenas, devido ao seu custo elevado e construídas em grande parte com materiais de produção alienígena que dispensam mão-de-obra e recursos regionais.

$\mathrm{Na}$ agricultura pode-se citar o fato de que na Europa a ampliação do solo agrícola se conseguiu com a destruição dos bosques originais. Tal técnica, que pode ter sentido nos solos estáveis e ricos em húmus das regiões temperadas e frias, é suscetivel de efeitos catastróficos quando aplicada às matas tropicais de solos pobres e instáveis.

A lista de exemplos poderia estender-se quase indefinidamente, mas basta recordar, para terminar, o efeito social da introdução de tecnologias e do conseqüente uso intensivo de capital em sociedade, onde o fator escasso é o capital e a mão-de-obra é abundante.

A posição dominante a nível mundial dos países desenvolvidos permitiu-lhes compensar alguns dos efeitos negativos das tecnologias utilizadas. 0 exemplo mais recente é a tendência a instalar nos países em desenvolvimento as indústrias mais poluentes ou aquelas que pela sua relativamente baixa rentabilidade já não se adequam aos altos níveis de vida dos países centrais. Esta política, ainda que não formulada tão explicitamente como agora, teve sua origem no passado. $O$ crescimento e a diversificação do consumo nos países avançados trouxe como conseqüência que as tecnologias utilizadas, as quais a princípio se circunscreviam aos recursos dos próprios países, exigissem cada vez mais, recursos externos (petróleo, metais não-ferrosos, borracha vegetal, produtos agrícolas tropicais, etc.) extraídos nos países em desenvolvimento. Os efeitos desta política na economia, no progresso social e no meio ambiente desses países são por demais conhecidos 
para que se torne necessário detalhá-los neste trabalho. Em resumo, os países industrializados puderam adequar as tecnologias utilizadas ao seu meio ambiente natural e humano, deslocando parte dos seus efeitos nocivos para a periferia. É evidente que os países em desenvolvimento, ao importar tais tecnologias (o que implica importar também os mesmos padrões de consumol já não tiveram a possibilidade de fazer apelo ao mesmo expediente para reduzir o seu efeito ambiental.

\section{Controle do efeito ambiental}

Dado que as tecnologias modernas e seu modo de aplicação são a expressão de um conceito de desenvolvimento, seu efeito sobre o meio ambiente não pode eliminar-se sem profundas transformações sócio-econômicas. Esses efeitos, todavia, não são totalmente irreversíveis e podem ser atenuados até a níveis toleráveis, pelo menos a curto e médio prazo. Para que isto seja possível, requerem-se duas condições: que a população afetada tenha consciência do dano e da sua origem e possua a capacidade de atuação para exigir uma solução; que a sociedade implicada possua os conhecimentos e os recursos humanos materiais necessários para idealizar e aplicar soluções.

No que diz respeito à primeira condição, as diferenças entre os países industrializados e os países em desenvolvimento são evidentes, sendo que nos primeiros, os níveis de interação social, de participação política e de educação alcançados, fazem com que a população, na sua maioria, tenha acesso aos meios de informação e, através de múltiplas formas de organização, estruturadas ou não, possa exercer pressão sobre setores públicos relacionados com os seus problemas. Isso se vê claramente pelo fato de que, não obstante os problemas ambientais serem mais graves em muitos dos países pobres, é nos países ricos que se origina o movimento ecológico, o qual afeta grandes setores da população até o ponto de manisfestar-se em organizações políticas, como na França, por exemplo. Fica cada dia mais dificil construir nos países centrais grandes instalações potencialmente poluentes sem ter em conta a opinião das populações afetadas, as quais utilizam todos os meios possíveis, inclusive a ação direta, para obstaculizar esses projetos. As manifestações contra a construção de usinas nucleares, de grandes aeroportos, etc. são bem conhecidas. Em outros campos de menor repercussão publicitária, ainda que talvez mais importantes, a pressão da opinião pública também tem obtido resultados significativos: o aumento do controle sobre a qualidade dos alimentos e produtos farmacêuticos (a U.S. Food and Drug Administration, é um exemplo disso), as regulamentações mais estritas sobre os residuos poluentes das indústrias, a "recuperação" dos rios, o rigoroso con- trole sobre a emissão dos gases dos automotores, a eliminação em vários países europeus dos avisos comerciais fora das áreas urbanas, etc.

Ainda que seja certo que todas essas medidas não passem de paliativos, que não atingem a raiz do problema, não é menos certo que, em parte graças a esta tomada de consciência do perigo ambiental, as comunidades dos países centrais começam a questionar os valores implícitos num conceito de "progresso" que ameaça destruir a sua própria base de sustentação.

Para a maior parte da população dos países subdesenvolvidos, submersos numa pobreza qua alcança níveis degradantes, o problema da deterioração ambiental assume escassa importância. Comparada com as suas condições de vida normais, a degradação do meio ambiente físico, na sua forma de esgotamento ou contaminação dos recursos naturais, pode considerar-se de dimensões insignificantes. A degradação visível do meio ambiente físico só alcança realmente, de uma forma ou de outra, aquela pequena porção da humanidade que foi a principal beneficiária dos recursos em questão; para a maior parte da humanidade, que permaneceu submersa, essa degradação é, quando muito, de significado marginal no cômputo da preocupação diária de suas vidas, que é a de sobreviverem como seres humanos; nessa luta pela sobrevivência uma melhoria do ambiente físico, per se, sem uma mudança social, oferece uma esperança mínima.

Este total divórcio de interesses entre os setores minoritários privilegiados e as massas carentes reflete-se na maneira como se encara geralmente o problema ambiental na América Latina. A discussão do tema - e sobretudo o começo de atuação centrou-se fundamentalmente nos efeitos da poluição em algumas das grandes capitais (México, Santiago e São Paulol onde, não obstante as favelas, se concentra a população de mais alto nível econômico e educacional. A contaminação das classes pobres nos bairros periféricos das grandes cidades e nas zonas rurais continua sendo um tema fundamentalmente de intelectuais, com um mínimo ou nenhum reflexo na ação concreta.

As razões da indiferença dos setores privilegiados perante as formas mais agudas da deterioração ambiental, em sentido amplo, são muitas, mas as principais podem facilmente ser identificadas. Em primeiro lugar, os setores em que se concentra o poder econômico e político podem, pela sua exigüidade, subtrair-se com relativa facilidade aos efeitos diretos dessa degradação. Em segundo lugar, as massas mais afetadas não possuem meios de pressão diretos, dada a sua quase nula participação nos mecanismos políticos de decisão; de resto, quando logram ultrapassar esses mecanismos institucionais 
e fazer sentir a sua existência, têm sempre reinvindicações muito mais prementes do que as relacionadas com o meio ambiente.

Um exemplo bem revelador de como esta marginalização de grandes setores da população influi nas opções tecnológicas é o caso dos sistemas de transporte adotados nas grandes cidades da América Latina. Poucos decênios atrás, quando essas cidades começaram a expandir-se rapidamente, apresentou-se uma alternativa para a solução do problema do transporte público: ou o transporte coletivo ou o automóvel, este último essencialmente individual. Em várias cidades le a do México é talvez o caso mais elucidativol optou-se pelo transporte individual, construindo-se assim a rede viária urbana em grande parte baseada em estradas de alta velocidade, com poucos acessos e que serviam especialmente as zonas residenciais de mais altos rendimentos. Para a grande massa da população, que não tem acesso econômico ao automóvel, o transporte aos locais de trabalho em meios de transporte escassos e ineficientes representa um gasto desproporcionado de tempo e de energia.

Por outro lado, esta opção tecnológica tem outras conseqüências negativas, como o aumento da contaminação atmosférica, o incremento do investimento em infra-estruturas, dados o elevado custo e baixo rendimento unitário das vias especiais de tráfego e, sobretudo, o custo social, já que essas infraestruturas favorecem preferencialmente uma minoria privilegiada. Finalmente, esta opção acaba por não resolver nem sequer o problema do setor social a que se dirigia, como o prova o congestionamento crescente do trânsito motorizado.

É interessante comparar essa opção tecnológica com a adotada nas grandes cidades dos países europeus mais industrializados. Nestes, onde a porcentagem da população com acesso ao automóvel é muito mais alta do que nos países em desenvolvimento, a opção determinante dos poderes públicos foi, no entanto, pelo transporte coletivo e a ele se subordinou a maior parte da infra-estrutura. O mesmo sucedeu em países da América Latina com um rela+ivamente maior desenvolvimento: o caso mais representativo é o da cidade de Buenos Aires, onde também se optou pelo transporte coletivo.

A explicação dessas diferentes opções, com diversos resultados sociais e ambientais, é a mesma no que se refere à proteção do meio ambiente. Nos países desenvolvidos, o grau de integração social alcançado tornou impossível ignorar as necessidades da maioria da população; por outro lado, nos países subdesenvolvidos a marginalização econômica, política e social das massas privou-as de toda a participação, direta ou indireta, na solução dos problemas tecnológicos que as afetam. Exemplos similares po- dem encontrar-se facilmente em outras áreas tecnológicas, como a habitação, os serviços de saúde, etc.

No que diz respeito à capacidade para controlar a deterioração do meio ambiente pressupondo-se uma decisão política de fazê-lo também são bem claras as diferenças entre os países desenvolvidos e os em desenvolvimento. Os primeiros são os criadores das tecnologias em uso e possuem por conseqüência o conhecimento e os meios para modificá-las ou substituí-las conforme for mais conveniente, e os segundos, receptores passivos dessas tecnologias, carecem dessa capacidade, encontrando-se, portanto, quase impotentes para controlar ó efeito das mesmas, que lhes são exógenas. Esta situação se agrava como efeito de dois fatores. Primeiramente, porque, dadas as diferenças ambientais entre olugar de origem das tecnologias e os países receptores, os efeitos não são necessariamente os mesmos e por isso as medidas tomadas nos países centrais nem sempre são aplicáveis aos periféricos. Um exemplo bem esclarecedor é o deslocamento de mão-de-obra, provocado pelas tecnologias intensivas de capital, tanto nas zonas rurais, como nas urbanas, com a conseqüente marginalização de grandes setores de população e o aumento da disseminação da pobreza. Esse efeito não ocorre nos países industrializados com diferente dotação de fatores de produção e, portanto, a solução do problema só pode resultar da iniciativa dos países afetados. Nos aspectos puramente físicos do problema cabe mencionar os métodos de cultivo intensivo, que são razoáveis em países com solos ricos e estáveis, mas que provocam a rápida degradação e erosão dos solos quando praticados em diferentes condições ecológicas. O segundo fator é que algumas medidas de controle aplicadas nos países desenvolvidos redundam em imediato prejuízo para os países em desenvolvimento, os quais se vêem assim excluídos dos seus possíveis benefícios. O primeiro caso - a que já nos referimos - é o do deslocamento para a periferia das atividades produtoras poluentes. $\mathrm{O}$ segundo caso refere-se ao fato de produtos, cujo uso se proibe nos países centrais dado o seu efeito negativo sobre a saúde ou o meio ambiente, continuarem sendo fabricados para exportação para o Terceiro Mundo. Apenas a título ilustrativo, pode mencionar-se a exportação de medicamentos já proibidos ou não autorizados nos seus países de origem (principalmente os EUA), assim como a exportação de fertilizantes que já não se usam nesses países pelo seu efeito nocivo para a saúde.

Por outro lado, muitas das medidas de controle ambiental não dependem apenas de mudanças nas tecnologias utilizadas, mas também, e por vezes principalmente, de medidas que visam o comportamento social e se concretizam a nível familiar e individual: manutenção de condições higiênicas, inclu- 
sive nos lugares públicos; profilaxia e precauções sanitárias com referências, sobretudo, às moléstias contagiosas; controle da erosão dos solos agrícolas; proteção da flora e fauna, etc. Todas estas medidas requerem o apoio maciço da população e este só se consegue a partir das seguintes condições: níveis de educação e informação que permitam criar entre a população uma consciência da natureza do problema e das suas possíveis soluções; e consenso social baseado no convencimento de que essas medidas redundam numa melhoria das condições de vida e na confiança depositada nas autoridades públicas promotoras dos programas.

Nos países desenvolvidos as duas condições se verificam em maior ou menor grau - a primeira, sobretudo - e, com isso, o comportamento social melhorou consideravelmente nos últimos anos no que diz respeito à proteção do meio ambiente. Em grande número dos países subdesenvolvidos, em contrapartida, não se verifica nenhuma das condições, faltando especialmente a segunda.

Quando existe consenso baseado na confiança outorgada às autoridades públicas, os problemas resultantes das imperfeições educacionais e dos sistemas de informação podem ser superados, como a China o demonstra. Nesse país o grau de alfabetização é relativamente baixo - devido fundamentalmente à própria natureza do idioma escrito - mas o alto consenso alcançado, em conseqüência, sobre- tudo, do alto grau de participação nos assuntos que se dirigem à vida diária das pessoas, tornou possível mobilizar a população para programas relacionados com a melhoria do meio ambiente em geral. Um dos índices mais efetivos nesse sentido é a rápida queda da mortalidade infantil, devida, sobretudo, à aplicação maciça de medidas preventivas de higiene e saúde.

\section{Suscetibilidade à deteriorização ambiental}

Um último fator que deve levar-se em conta é a suscetibilidade aos efeitos da contaminação física. O mesmo tipo e grau de contaminação afeta mais as pessoas debilitadas por uma subalimentação e pelas enfermidades endêmicas com pouco ou nenhum acesso a serviços médicos, do que a população dos países ricos, a qual, na sua grande maioria não padece dessas déficiências. Esse é um fator que geralmente se esquece quando se projeta radicar indústrias poluentes nos países em desenvolvimento, na implícita suposição de que o efeito sobre a população não irá ser mais danoso do que nos países de origem.

Em suma, a relação tecnologia - meio ambiente depende de como as tecnologias são criadas e transferidas e do caráter da comunidade em que vão inserir-se. Uma política ambiental só pode ter êxito se se levar em conta a inter-relação desses fatores. 


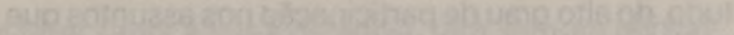

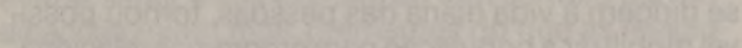

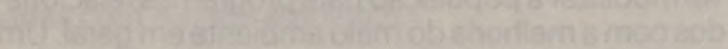

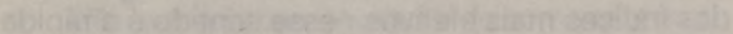

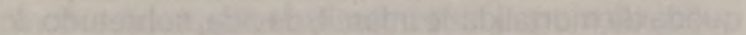

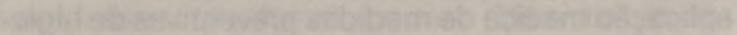

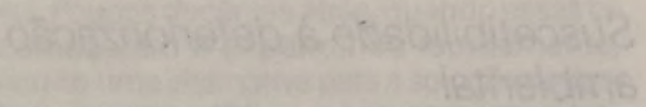

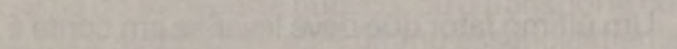

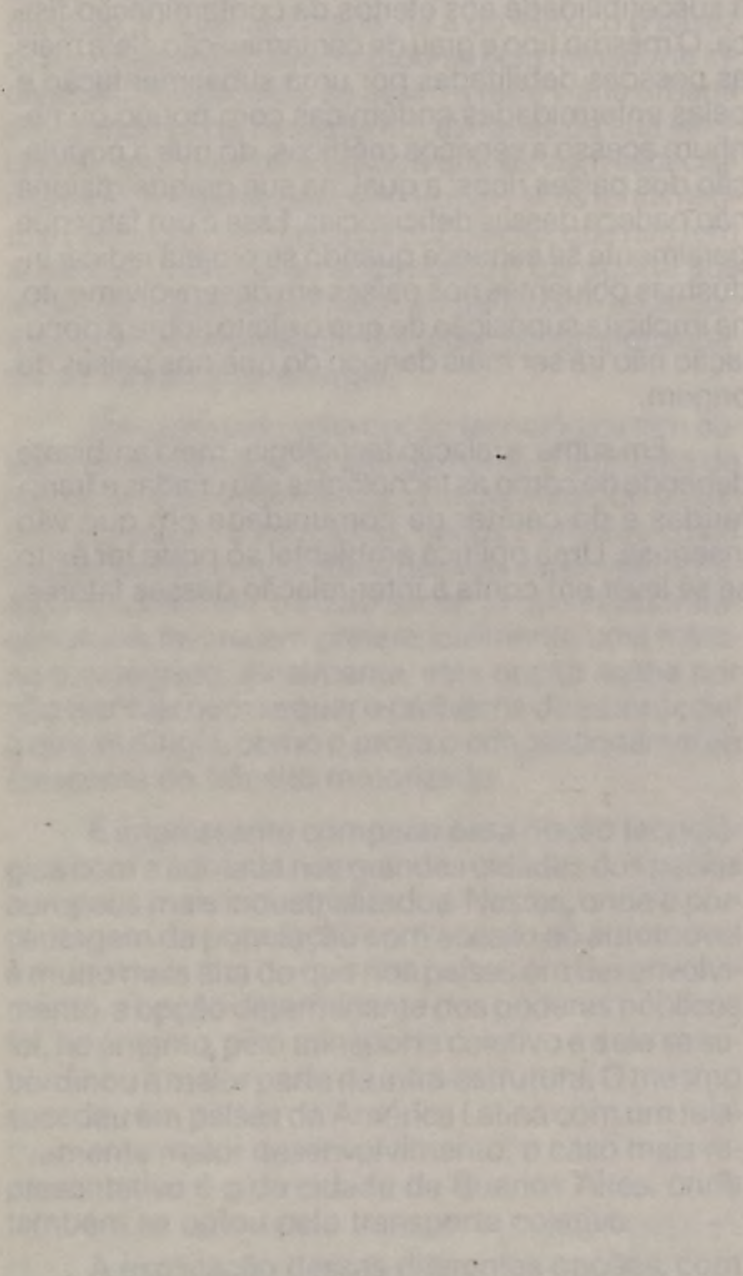

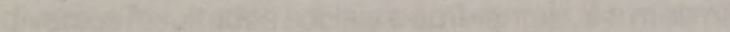

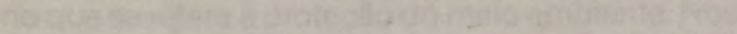

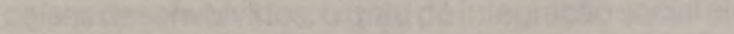

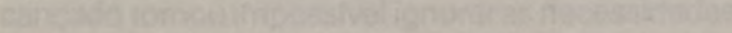

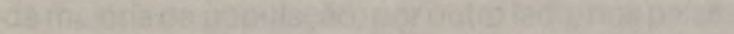

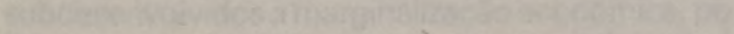

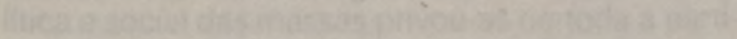

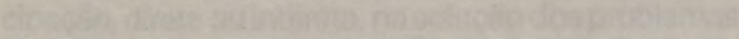

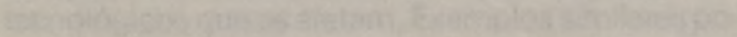
58
W

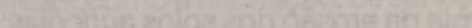

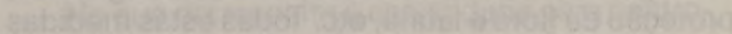

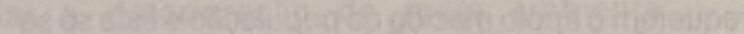

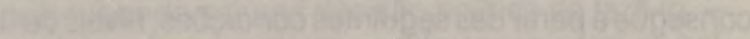

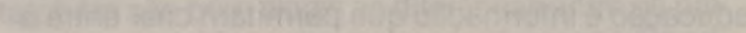

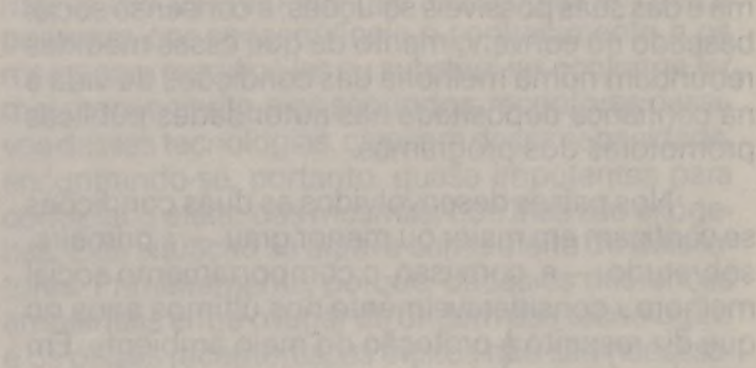

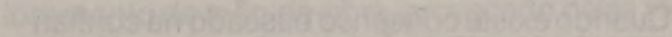

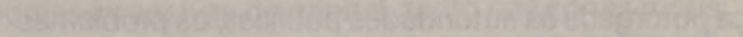

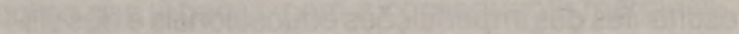

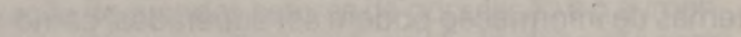

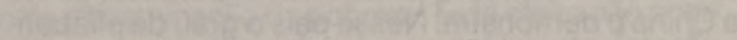

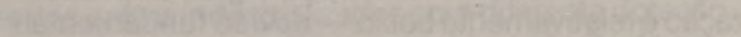

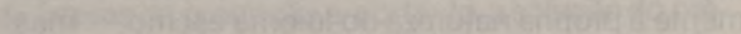

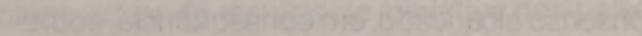
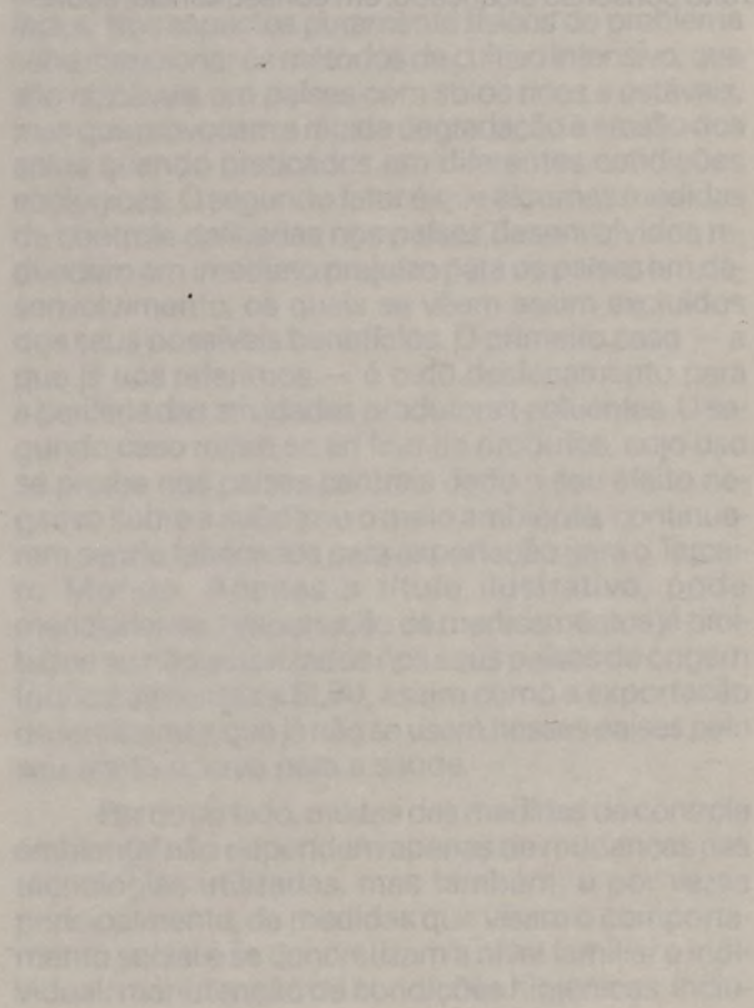